International Review of Research in Open and Distributed Learning Volume 20, Number 5

December - 2019

\title{
Familiarity, Current Use, and Interest in Universal Design for Learning Among Online University Instructors
}

\author{
Carl D. Westine, Ph.D., Beth Oyarzun, Ph.D., Lynn Ahlgrim-Delzell, Ph.D., Amanda Casto, Cornelia Okraski, Gwitaek \\ Park, Julie Person, and Lucy Steele \\ The University of North Carolina at Charlotte
}

\begin{abstract}
This study investigated online faculty familiarity, course design use, and professional development interest regarding universal design for learning (UDL) guidelines. The researchers surveyed all 2017 to 2018 online faculty at a large university in the southeastern United States. Findings included $71.6 \%$ of faculty reporting familiarity with at least one UDL guideline, with most respondents indicating familiarity with guidelines relating to perception, expression, and communication. Faculty reported the highest implementation of UDL guidelines was for those suggesting options for comprehension as well as expression and communication; the lowest implementation was for those suggesting options for physical action as well as language and support. Survey results also indicated high to moderate interest in learning more about all UDL guidelines, with emphasis on comprehension, persistence, and expression. This study suggests that faculty members desire UDL training and offers possibilities for planning and implementing such professional development in areas targeted to best meet the needs of online faculty.
\end{abstract}

Keywords: universal design for learning, online teaching, faculty development, higher education 


\section{Introduction and Overview}

Expanding the delivery of courses online presents an ongoing challenge to universities that aim to provide all students with comparable high-quality experiences that transcend all delivery modalities. Typically, universities react to the changing needs of online students as they arise, but this increasingly places them in the precarious position of being able to react fast enough to the evolving environment. Universities must find new ways to adapt to the changing culture and needs of students while continuing to grow and virtually reach students.

Universal design for learning (UDL) is a framework designed to optimize learning for all, based on scientific evidence of how learning occurs (CAST, 2018). This framework has been widely used in the field of special education for learners with differing abilities (Keeler \& Horney, 2007; Rao, Ok, \& Bryant, 2014). While the UDL framework is less well-known in other disciplines, it may be useful to guide learning for all, given the new opportunities and challenges information technologies have presented to educational institutions. Because it has not received as much attention in online contexts, the framework presents a radical shift to one of proactivity for course designers, where planning online courses is executed to optimize the learning environment for all students prior to delivery.

As universities align their missions to promote a culture of equity, it is important to explore the viability of UDL as a framework to promote accessibility and achieve success, particularly in response to expanding course delivery options. In this study we report on a survey of faculty perspectives of UDL as a first step in a broader needs assessment of UDL for online teaching at a university with an equity-focused mission. The online faculty knowledge of and interest in the application of UDL guidelines in online course design was assessed to help document the current state of UDL guidelines application in online course design.

\section{Universal Design for Learning}

UDL is a conceptual framework that examines how to provide instruction that meets the learning needs of all students. UDL forces educators to proactively reflect on learning needs for learners with and without disabilities. Within the UDL framework there are three primary principles: (a) multiple means of representation, (b) multiple means of engagement, and (c) multiple means of expression. First, representation speaks to using a variety of strategies, methods, and tools that present class information and content in different forms to proactively meet students' needs and learning preferences. Next, expression and action provide students multiple means of demonstrating their learning. Finally, engagement looks at strategies such as offeringstudent choice to increase the level of activelearning for students, and encourages the use of self-reflection and self-monitoring for students. As seen in Table 1, each UDL principle has three guidelines (CAST, 2018).

The benefits of using UDL are well documented in the face-to-face classroom. For example, Al-Azawei, Serenelli, and Lundqvist (2016) conducted a content analysis of 12 studies regarding the adoption of UDL principles from 2012 to 2015. Ten of the studies were conducted in traditional or blended classrooms, and only two studies were online. Nearly all yielded positive results from implementing UDL principles. The authors suggested that material designed with UDL principles could effectively reach a large variety of learners with different levels of prior knowledge, abilities, and education from various cultural backgrounds. 
Capp (2017) pointed to similar benefits in a meta-analysis of 18 studies between 2013 and 2016 for students across varying abilities. In both the Al-Azawei et al. (2016) and Capp (2017) syntheses, the positive findings spanned multiple disciplines. There were also benefits for teachers. Specifically, Katz (2012) identified a reduction in stress, while Kumar and Wideman (2014) found there to be better preparation through reduced workload. Additionally, Capp (2017) emphasized the role of teacher preparation programs which demonstrate both the student and teacher perspective as a critical juncture for introducing UDL principles, for example through lesson planning.

Table 1

A Description of UDL Principles and Guidelines

\begin{tabular}{|c|c|c|}
\hline Principles & Guidelines & Description \\
\hline \multirow[t]{3}{*}{$\begin{array}{l}\text { Principle 1: Providing multiple } \\
\text { means of representation }\end{array}$} & 1: Perception & $\begin{array}{l}\text { Alternatives for auditory and visual information or offer } \\
\text { ways of customizing the display of information }\end{array}$ \\
\hline & $\begin{array}{l}\text { 2: Language, mathematical } \\
\text { expressions, and symbols }\end{array}$ & $\begin{array}{l}\text { Clarify vocabulary, symbols, syntax, and structure; promote } \\
\text { understanding across languages }\end{array}$ \\
\hline & 3: Comprehension & $\begin{array}{l}\text { Activate or supply background knowledge; highlight } \\
\text { patterns, critical features, big ideas, and relationships; } \\
\text { guide information processing and visualization }\end{array}$ \\
\hline \multirow[t]{3}{*}{$\begin{array}{l}\text { Principle 2: Providing multiple } \\
\text { means of action and expression }\end{array}$} & 4: Physical action & $\begin{array}{l}\text { Vary the methods for response and navigation; optimize } \\
\text { access to tools and assistive technologies }\end{array}$ \\
\hline & $\begin{array}{l}\text { 5: Expression and } \\
\text { communication }\end{array}$ & $\begin{array}{l}\text { Use multiple media for communication; use multiple tools } \\
\text { for construction and composition; build fluencies with } \\
\text { graduated levels of support for practice }\end{array}$ \\
\hline & 6: Executive functions & $\begin{array}{l}\text { Guide appropriate goal setting; support planning and } \\
\text { strategy development; facilitate the management of } \\
\text { information and resources; enhance capacity for } \\
\text { monitoring progress }\end{array}$ \\
\hline \multirow[t]{3}{*}{$\begin{array}{l}\text { Principle 3: Providing multiple } \\
\text { means of engagement }\end{array}$} & 7: Recruiting interest & $\begin{array}{l}\text { Optimize individual choice, autonomy, relevance, value, } \\
\text { and authenticity; minimize threats and distractions }\end{array}$ \\
\hline & $\begin{array}{l}\text { 8: Sustaining effort and } \\
\text { persistence }\end{array}$ & $\begin{array}{l}\text { Heighten salience of goals and objectives; vary demands } \\
\text { and resources to optimize challenge; foster collaboration } \\
\text { and community; increase mastery-oriented feedback }\end{array}$ \\
\hline & 9: Self-regulation & $\begin{array}{l}\text { Promote expectations and beliefs that optimize motivation; } \\
\text { facilitate personal coping skills; develop self-assessment } \\
\text { and reflection }\end{array}$ \\
\hline
\end{tabular}

Note. Adapted from “Universal design for learning guidelines version 2.2,” by CAST, 2018

(http:// udlguidelines.cast.org).

Unfortunately, much less is known about the use of UDL in an online environment where the delivery modality can have differing impacts on experiences for students, depending on their needs. Specifically, some higher education students may find online courses eliminate the need to address a visible disability, possibly enhancing their experiences (Barnard-Brak \& Sulak, 2010). Other students with disabilities may be more discouraged by having to ask for accommodations in an online environment than in a face-to-face 
setting (Ryan, 2007). When an online course is designed to meet UDL, it eliminates the need for retrofitting courses to accommodate the needs of specific subpopulations including students with disabilities, which further delays mastery (Casper \& Leuichovious, 2005). Instead, UDL provides flexibility to all students to engage in a course in a way that is optimal for them, whether needing an accommodation or not. Hence, UDL is applicable to all learners, and in all settings-even online.

While the topic of UDL is not new, its application to online environments is still rare. A study conducted by He (2014) identified increased confidence in the content as well as self-efficacy tied to future teaching, particularly online. Additionally, Hall, Cohen, Vue, and Ganley (2015) noted positive effects on reading processes.

Furthermore, although not empirical, Tobin (2014) argued that applying UDL principles would help increase retention rates and ease technical problems with accessing materials, given the rise in use of various devices to access course content. Students value multiple options to access content and multiple options to demonstrate mastery of content throughout courses (Rao \& Tanners, 2011). For example, if a student is traveling, and has limited Wi-Fi connection and only a mobile device, s/ he could opt to access the text version of the content instead of a lecture video that may not be readily accessible given the circumstances.

One possible reason for the lack of empirical research is limited guidance on how to implement UDL in the online environment, and how it differs from existing, more commonly used quality frameworks such as Quality Matters (QM; Quality Matters, 2018). Indeed, while there are similarities between UDL and the QM standards, the interpretation or application of the QM standards can be different. For example, an instructor may apply the use of a variety of instructional materials by using different instructional materials in each module (e.g., a lecture video in module 1, a research article in module 2). Although similar, UDL recommends providing various methods to access the content. This suggests having the same content represented in multiple ways which differs from having a variety of instructional materials in various modules.

Research does emphasize an incremental approach to adoption, highlighting feasible avenues for practitioners to consider as they explore the use of UDL in their online courses. Recently, Robinson and Wizer (2016) integrated the QM and UDL frameworks to create a set of guidelines for the development of quality online courses. Their recommendations focused on taking small steps to develop content, and then design the course with the students' success in mind: (a) begin with a small amount of content, (b) recruit students to make change decisions, (c) provide various methods to access the content, (d) provide choices for students to demonstrate understanding, and (e) provide multiple content engagement methods. Relatedly, Dell, Dell, and Blackwell (2015) drew off a University of Arkansas recipe for developing online UDL courses to also highlight starting small and utilizing backward design. Backward design prioritizes tailoring the course content to established course objectives (Wiggins \& McTighe, 2005). Finally, Tobin (2014) also recommended five strategies for faculty to apply UDL principles to online course design: (a) build the text foundation, (b) create video and audio alternatives, (c) allow students to express their understanding of material in their own way, (d) break content into chunks, and (e) use tools that are userfriendly. While the collective recommendations span the UDL principles, they also specify generating content alternatives for perception and adding flexibility for expression as starting points for UDL adoption. 
Unquestionably, more research and evaluation will be needed to provide empirical guidance on the topic of UDL adoption in an online context.

\section{The Need for Universal Design for Learning in an Equity-Focused Institution}

An equity-focused mission. While UDL can provide benefits to all students and even teachers, it is unique in its emphasis on designing for equity, and therefore it may be a better option for institutions of higher education that are equity focused. According to the Americans With Disabilities Act of 1990 (1991), all American universities are prohibited from discrimination against students with disabilities. Adherence to ADA can be accomplished in multiple ways, depending on perspective, namely reactive or proactive. Providing accommodations such as closed captions for an instructional video after the course is in progress, for example, is reactive rather than proactive. The UDL framework can assist with ADA compliance proactively, in addition to being culturally responsive.

In addition to $\mathrm{ADA}$ compliance, some university mission statements include equity-focused language. Below are several statements quoted from a university mission that characterizes this equitable focus:

- An accessible and affordable quality education that equips students with intellectual and professional skills, ethical principles, and an international perspective;

- A robust intellectual environment that values social and cultural diversity, free expression, collegiality, integrity, and mutual respect;

- A safe, diverse, team-oriented, ethically responsible, and respectful workplace environment that develops the professional capacities of our faculty and staff (The University of North Carolina at Charlotte, 2014, “University Vision and Values Section," para. 1).

Some ways that universities can meet this mission is through delivery of high-quality online courses, and the opportunity for faculty who teach online to obtain QM online course certification using the higher education rubric standards (Quality Matters, 2018). This is a proactive approach for designing high-quality online courses, but the interpretation of the QM standards may not be ADA compliant. Incorporating the UDL guidelines, in addition to the QM rubric, may result in an online course that is more culturally responsive to diverse audiences.

According to Eberle and Childress (2006), in the design of online courses it is imperative to consider the culturally diverse audience they will reach; however, the values of "social and cultural diversity, free expression, collegiality, integrity, and mutual respect" (The University of North Carolina at Charlotte, 2014, "University Vision and Values Section," para. 1) are not explicitly represented in the quality rubric adopted by the university at which this study took place. The UDL principles were created to ensure that all individuals have equal opportunities to learn (CAST, 2018) and could be beneficial in guiding the design of online courses to support this part of the university's mission statement. Therefore, UDL provides an appropriate framework by which to consider online course design given an equity-focused mission.

Growth of online courses. Aligning online course design with an institution's goal to provide equitable access to a diverse body of students is increasingly important given the growth of online offerings 
as a share of the total course offerings at institutions in the past two decades. According to Allen and Seaman (2016), more than a quarter of higher education students are now enrolled in at least one online course. This trend has also occurred at the university where this study took place, where the number of fully online courses has doubled in five years (see Figure 1).

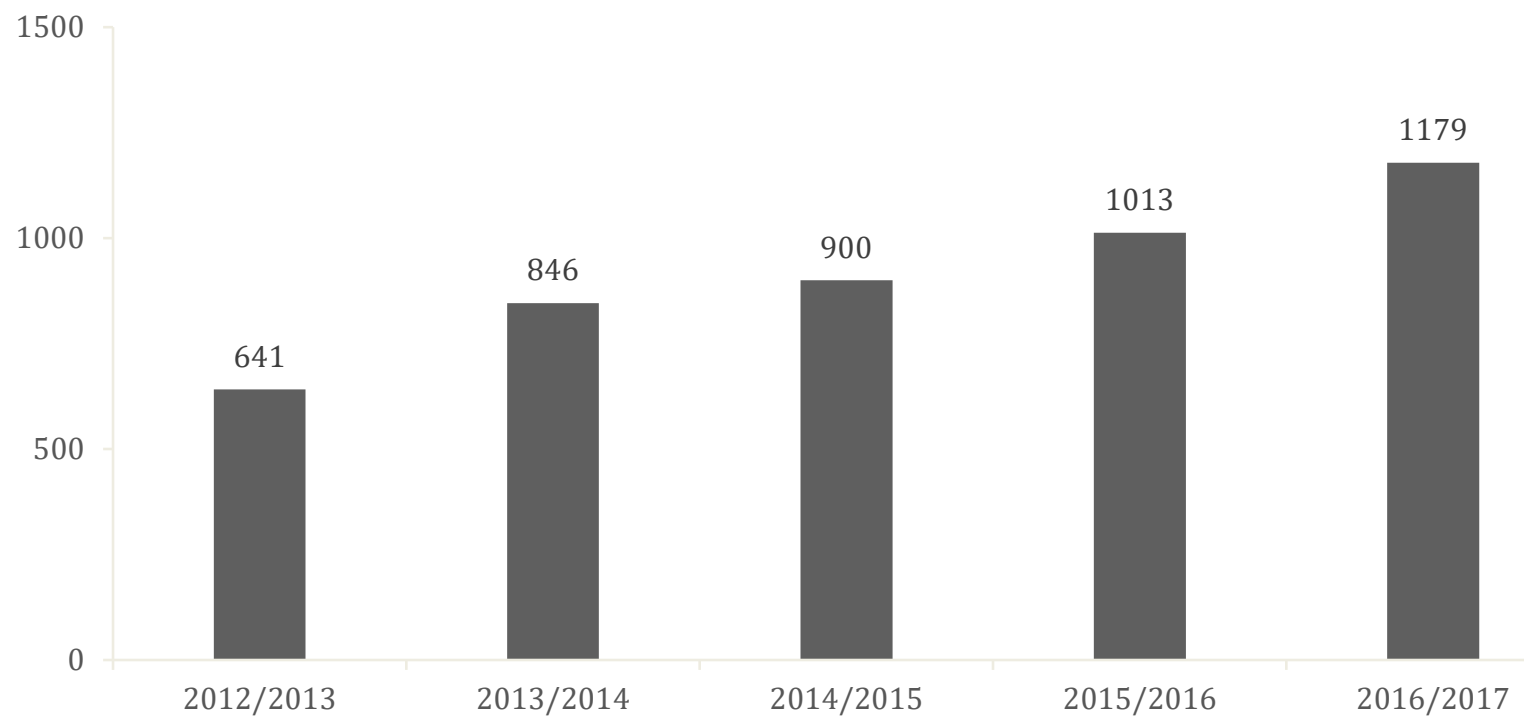

Figure 1. Rapid increase in the number of fully online course sections across time.

\section{Research Purpose}

Given the growth of online offerings, and a mission of providing equitable access to a diverse body of students, the purpose of this research was to explore faculty familiarity, use, and interest in learning more about the UDL guidelines in the online learning environments. We conducted a survey of online faculty at a large southeastern university in the United States who had taught a fully online course during the 20172018 academic year, in order to document their practice, as well as identify knowledge gaps and interest in professional development opportunities with respect to UDL. Specifically, we were interested in answering the following research questions:

1. To what extent are online faculty familiar with UDL guidelines?

2. To what extent do online faculty use UDL guidelines in course designs?

3. What are online faculty interests and priorities with respect to learning more about UDL guidelines for course design?

\section{Method}

This survey research study was guided by the social exchange theory and tailored design method (Dillman, Smyth, \& Christian, 2014). This theory and design method are used in order to embed reciprocity, credibility, and trustworthiness in survey design and dissemination, in an effort to obtain representative 
response rates, recognizing the importance of knowing the audience. Survey administration took place in spring 2018.

\section{Sampling Frame}

The sampling frame consisted of 425 university employees who had taught at least one fully online course during the 2017-2018 academic year (i.e., three semesters; summer, fall, spring). Names and emails were provided to the researchers by the university's Office of Distance Education. The university is a public institution offering undergraduate, graduate, and professional programs affiliated with the state system located in an urban area of the southeastern United States. The frame was narrowed to 355 faculty members after removing individuals who were no longer university employees.

\section{Instrumentation}

A questionnaire was developed specifically for this study and was guided by recent articles about UDL and online instruction (Bauder \& Simmons, 2017; Eberle \& Childress, 2006; Tobin, 2014). The instrument was designed to collect the necessary information to describe faculty familiarity with, use of, and interest in UDL. The instrument also included several demographics questions to describe the sample. Question options included interval scales, select all that apply, and ranking. Options labelled other were provided as a space for writing individual responses.

The survey was piloted with six university faculty members who were not included in the sampling frame. Three used a think aloud method. The other half tested skip patterns and determined the time needed to complete the questionnaire, finally set at 15 to 20 minutes.

\section{Administration Procedure}

The survey was administered using SurveyShare, an online survey program, between March 22, 2018 and April 12, 2018. Personalized e-mail invitations described the study and linked to a consent form and online survey. Two reminder e-mails were sent to non-responders, approximately one week apart on different days and times. A single lottery-based incentive valued at $\$ 100.00$ was offered to participants.

\section{Results}

The survey had three distinct sections aligning to the research questions to identify familiarity with UDL, use of UDL in a particular context, and interest in learning more about UDL. Below, we present descriptive information about the respondents, and then subsequently address each of the three sections.

\section{Respondents}

Response rates. In total, we received 150 responses, a $42.2 \%$ response rate. This is slightly lower than the targeted 186 responses required to maintain a confidence level of $95 \%$ and a margin of error of 5\% in order to be considered representative of the sampling frame (Krejcie \& Morgan, 1970). However, given the lack of research in this area we felt these results still contribute to the knowledge base. 
Figure 2 summarizes the response rates and attrition for each section of the survey. Of the 150 responses, nine did not respond to any of the questions and were not included in the analyses. Of the 141 respondents who completed the first section, there were 101 (71.6\%) respondents who indicated familiarity with at least one UDL guideline. Beyond the opening questions, some attrition appears to have taken place. Our sampling frame of instructors was based on a registry of online courses during this time period, but only 124 (87.9\%) indicated they taught an online course between summer 2017 and spring 2018. Additionally, not all respondents who taught a course during the year contributed to the course design. J ust 107 (86.3\%) of the 124 indicated designing at least some aspect of the course; 83 (67\%) of these were the sole designer.

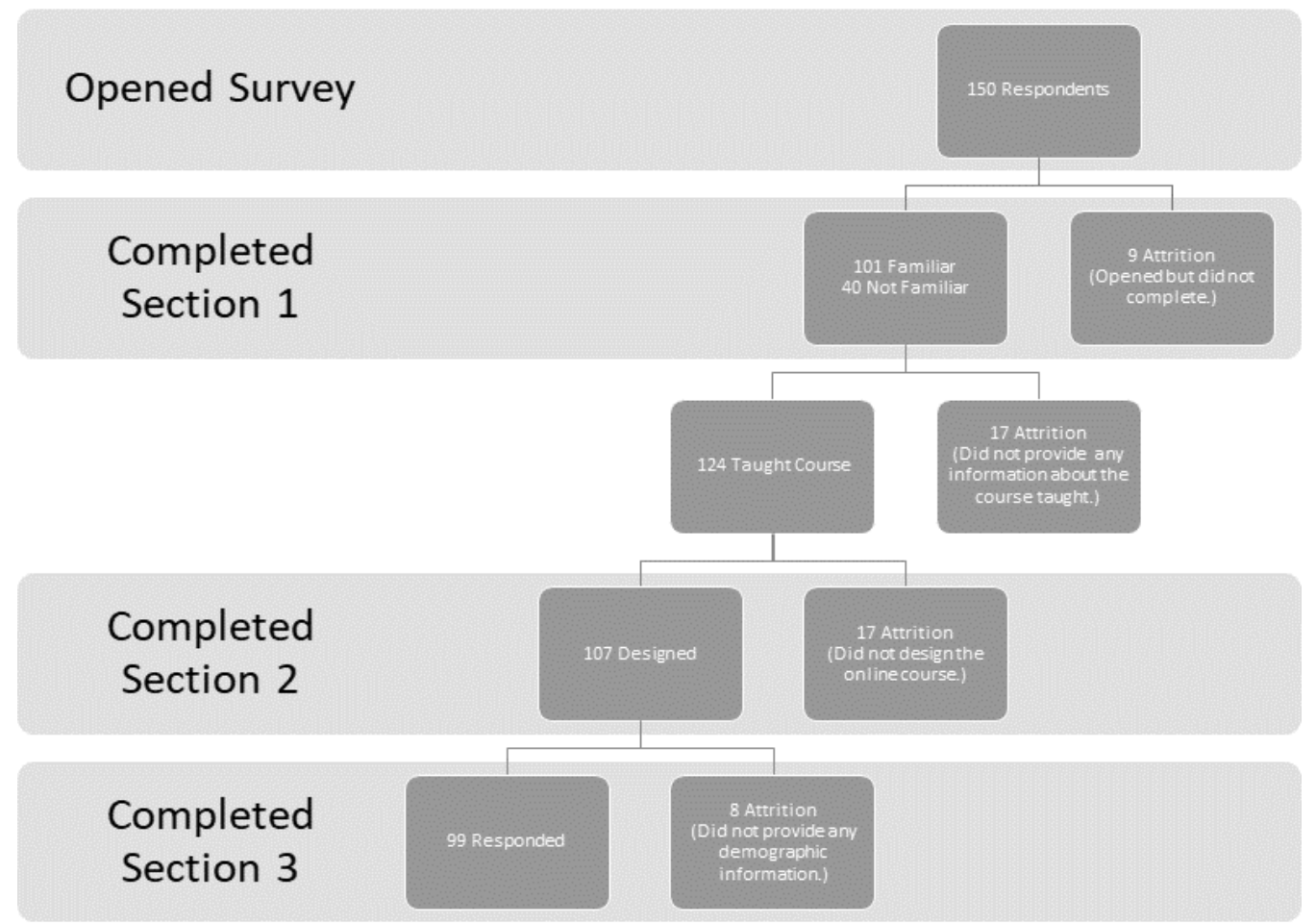

Figure 2. Response rates and attrition points for each of the three survey sections.

Given the observed attrition, there is a potential bias towards familiarity with UDL in the results of the final survey sections. We compared the groups of respondents who dropped out of the study after indicating UDL familiarity with those who stayed in and found respondents for the remaining questions were more likely to be familiar with at least one of the UDL guidelines, $\chi^{2}(2, N=141)=8.38, p=.0038$.

Demographics. Respondents self-reported their faculty role or rank, typical online student audience, years of experience teaching online, number of online courses taught, and information on specialized training for online teaching (see Table 2). Tenured and tenure-track faculty represented approximately one-third of the respondents (33.7\%). Faculty reported their online classes predominantly served undergraduate students (62.6\%). Additionally, the respondents were relatively new to online teaching. Typical online teaching experience was one to five years (42.4\%), but $21.2 \%$ of respondents reported having less than one year of experience. Consequently, the breadth of courses taught was also limited; about two-thirds (61.5\%) of faculty taught one to three online courses, and the median was two on 
a range from one to twenty courses. Half (55.4\%) of the faculty received training in QM, but few (12\%) in UDL.

Table 2

Characteristics of the Survey Respondents

\begin{tabular}{lcc}
\hline \multicolumn{1}{c}{ Characteristic } & $\mathrm{n}$ & $\%$ \\
\hline Role or rank & 28 & 28.6 \\
Lecturer & 25 & 25.5 \\
Clinical & 24 & 24.5 \\
Tenured & 9 & 9.2 \\
Tenure track & 9 & 9.2 \\
Adjunct & 3 & 3.1 \\
Other & & \\
Online course audience(s) & 62 & 62.6 \\
Undergraduate & 47 & 47.5 \\
Graduate & 14 & 14.1 \\
Post baccalaureate or certificate & & \\
Years of online teaching experience & 21 & 21.2 \\
Less than 1 year & 42 & 42.4 \\
1 to 5 years & 20 & 20.2 \\
6 to 10 years & 12 & 12.1 \\
11 to 15 years & 4 & 4.0 \\
More than 15 years & & \\
Number of online courses taught & 59 & 61.5 \\
1 to 3 courses & 20 & 20.8 \\
4 to 6 courses & 8 & 8.3 \\
7 to 9 courses & 7 & 7.3 \\
10 to 12 courses & 2 & 2.1 \\
13 or more courses & & \\
Training for online teaching & 76 & 82.6 \\
Canvas & 51 & 55.4 \\
Quality Matters & 11 & 12.0 \\
Universal design for learning & 19.6 \\
Other & & \\
\hline
\end{tabular}

Note. Characteristic sample sizes vary due to missing data or participants having selected multiple response options.

Since we were interested in describing online course design practices, the questions about use of UDL in a particular context were only asked of those 107 who identified as contributing to the course design. The final set of questions regarding interest in learning more about UDL and demographic information was available to everyone, but only 99 responses were provided.

\section{Familiarity with UDL}

Respondents were asked about their familiarity with the nine UDL guidelines (see Table 3). Forty respondents (28.4\%) reported that they were not familiar with any of the nine UDL guidelines. Among the remaining 101 online instructors, the median number of guidelines the faculty were familiar with was four. 
The two guidelines that faculty were most familiar were Guideline 1: Perception (59.6\%) and Guideline 5: Expression and Communication (60.3\%). When qualitatively asked to describe how they learned about UDL, responses fell into two main categories: professional development (e.g., workshops, conferences, coursework) and self-study (e.g., reading online or textbooks, personal experience.)

Table 3

Faculty Familiarity With Specific UDL Guidelines

\begin{tabular}{lcc}
\hline \multicolumn{1}{c}{ Guidelines } & \multicolumn{2}{c}{ Familiarity } \\
\hline 1: Perception & $\mathrm{n}$ & $\%$ \\
2: Language, mathematical expressions, and symbols & 84 & 59.6 \\
3: Comprehension & 53 & 37.6 \\
4: Physical action & 71 & 50.4 \\
5: Expression and communication & 61 & 43.3 \\
6: Executive function & 85 & 60.3 \\
7: Recruiting interest & 55 & 39.0 \\
8: Sustaining effort and persistence & 57 & 40.4 \\
9: Self-regulation & 56 & 39.7 \\
Not familiar with any guidelines & 67 & 47.5 \\
\hline
\end{tabular}

Note. Guidelines 1-3 represent the principle of multiple means for representation, guidelines 4-6 represent the principle of multiple means for action and expression and guidelines 7-9 represent the principle for multiple means for engagement.

\section{Current Status of UDL Online Practices}

The 107 respondents who indicated they designed an online course were asked to identify a specific online course for the purposes of this study. Table 4 details the reference courses faculty identified, by college. The courses reported span six of the seven colleges within the university. The colleges of liberal arts and sciences, education, and health and human services had the highest representation. 
Table 4

Faculty-Identified Reference Courses: Home College Within the University

\begin{tabular}{|c|c|c|}
\hline College & $\mathrm{n}$ & $\%$ \\
\hline Computing and informatics & 9 & 8.4 \\
\hline Education & 23 & 21.5 \\
\hline Engineering & 3 & 2.8 \\
\hline Health and human services & 19 & 17.8 \\
\hline Liberal arts and sciences & 34 & 31.8 \\
\hline Interdisciplinary & 1 & 0.9 \\
\hline University college (i.e., freshman experience) & 9 & 8.4 \\
\hline Not specified & 9 & 8.4 \\
\hline Total & 107 & \\
\hline
\end{tabular}

Table 5 displays the frequency and percent of use of UDL guidelines in the design of an online course. It also shows users' familiarity with the respective UDL guidelines. The guidelines used most frequently were Guideline 3: Comprehension (69.8\%) and Guideline 5: Expression and Communication (64.9\%). The guideline used least was Guideline 2: Language, Mathematical Expressions, and Symbols (38.8\%). Interestingly, familiarity was not a requirement for faculty use, as up to $15 \%$ of faculty who reported using a guideline were also unfamiliar with it.

In follow-up to using the guidelines, respondents were asked to report their level of implementation for each guideline. Table 6 displays the level of implementation for each guideline. A majority of online instructors reported a high to moderate level of implementation across the nine guidelines. In addition to being the most frequently used, Guidelines 3 and 5 regarding options for comprehension, expression, and communication were rated with the highest levels of implementation. 
Table 5

Faculty Use of UDL Guidelines in Online Course Design

\begin{tabular}{|c|c|c|c|c|}
\hline Guideline & $\mathrm{n}$ & $\%{ }^{a}$ & $\begin{array}{c}\text { \% familiar with } \\
\text { the UDL } \\
\text { guideline }\end{array}$ & $\begin{array}{c}\text { \% not familiar } \\
\text { with the UDL } \\
\text { guidelineb }^{b}\end{array}$ \\
\hline 1: Perception & 55 & 55.0 & 85.5 & 14.5 \\
\hline $\begin{array}{l}\text { 2: Language, mathematical expressions, } \\
\text { and symbols }\end{array}$ & 38 & 38.8 & 94.7 & 5.3 \\
\hline 3: Comprehension & 67 & 69.8 & 85.1 & 14.9 \\
\hline 4: Physical action & 40 & 42.1 & 87.5 & 12.5 \\
\hline 5: Expression and communication & 61 & 64.9 & 86.9 & 13.1 \\
\hline 6: Executive function & 42 & 46.2 & 90.5 & 9.5 \\
\hline 7: Recruiting interest & 44 & 48.4 & 93.2 & 6.8 \\
\hline 8: Sustaining effort and persistence & 45 & 50.6 & 95.6 & 4.4 \\
\hline 9: Self-regulation & 48 & 53.9 & 93.8 & 6.3 \\
\hline
\end{tabular}

Notes. Guidelines 1-3 represent the principle of multiple means for representation, guidelines 4-6 represent the principle of multiple means for action and expression and guidelines 7-9 represent the principle for multiple means for engagement.

aOnly faculty who designed some aspect of the online course were asked about using the UDL guidelines, and of the 107 individuals asked about their use of each guideline, responses were provided by 89 to 100 individuals, depending on the specific guideline.

bPercentage denominator is the number of faculty who indicated use of the specific UDL guideline. 
Table 6

Respondents' Self-Reported Level of Implementation of UDL Guidelines in Their Course Design

\begin{tabular}{|c|c|c|c|c|c|c|}
\hline \multirow[t]{2}{*}{ Guideline } & \multicolumn{3}{|c|}{ Very } & \multirow[b]{2}{*}{ Moderate } & \multirow[b]{2}{*}{ Low } & \multirow{2}{*}{$\begin{array}{l}\text { Very } \\
\text { low }\end{array}$} \\
\hline & $\mathrm{n}$ & high & High & & & \\
\hline 1: Perception & 55 & 10.9 & 40.0 & 43.6 & 5.5 & 0 \\
\hline $\begin{array}{l}\text { 2: Language, mathematical expressions, and } \\
\text { symbols }\end{array}$ & 37 & 13.5 & 35.1 & 43.2 & 5.4 & 2.7 \\
\hline 3: Comprehension & 66 & 9.1 & 47.0 & 37.9 & 6.1 & 0 \\
\hline 4: Physical action & 40 & 15.0 & 25.0 & 47.5 & 10.0 & 2.5 \\
\hline 5: Expression and communication & 60 & 16.7 & 43.3 & 40.0 & 0 & 0 \\
\hline 6: Executive function & 42 & 9.5 & 45.2 & 40.5 & 4.8 & 0 \\
\hline 7: Recruiting interest & 43 & 13.9 & 34.9 & 41.9 & 9.3 & 0 \\
\hline 8: Sustaining effort and persistence & 47 & 17.0 & 48.9 & 21.3 & 10.6 & 2.1 \\
\hline 9: Self-regulation & 48 & 8.3 & 47.9 & 39.6 & 2.1 & 2.1 \\
\hline
\end{tabular}

Note. Guidelines 1-3 represent the principle of multiple means for representation, guidelines 4-6 represent the principle of multiple means for action and expression and guidelines 7-9 represent the principle for multiple means for engagement.

Another follow-up question regarding use of the guidelines addressed respondents' level of comfort in applying the guidelines to online courses; Table 7 displays the results. Response options included: (a) I am comfortable mentoring others in the application of this UDL guideline, (b) I am comfortable applying this UDL guideline in my course without assistance, (c) I am comfortable applying this UDL guideline in my course with assistance, and (d) I am not comfortable applying this UDL guideline. Most respondents reported being able to implement the nine UDL guidelines without assistance. About $30 \%$ of respondents indicated they needed assistance applying six guidelines to their courses. 
Table 7

Respondents' Self-Reported Level of Comfort in Applying the UDL Guidelines They Implement

\begin{tabular}{lccccc}
\hline \multicolumn{1}{c}{ Guideline } & n & $\begin{array}{c}\text { Mentoring } \\
\text { others with } \\
\text { application } \\
(\%)\end{array}$ & $\begin{array}{c}\text { Applying } \\
\text { without } \\
\text { assistance } \\
(\%)\end{array}$ & $\begin{array}{c}\text { Applying } \\
\text { with } \\
\text { assistance } \\
(\%)\end{array}$ & $\begin{array}{c}\text { Not } \\
\text { comfortable } \\
\text { applying (\%) }\end{array}$ \\
\hline 1: Perception & 55 & 14.6 & 49.1 & 30.9 & 5.5 \\
2: Language, mathematical & 37 & 2.7 & 56.8 & 37.8 & 2.7 \\
$\quad$ expressions, and symbols & 66 & 13.6 & 56.1 & 27.3 & 3.0 \\
3: Comprehension & 40 & 17.5 & 37.5 & 37.5 & 7.5 \\
4: Physical action & 60 & 20.0 & 58.3 & 18.3 & 3.3 \\
5: Expression and communication & 42 & 21.4 & 57.1 & 19.1 & 2.4 \\
6: Executive function & 43 & 23.3 & 37.2 & 37.2 & 2.3 \\
7: Recruiting interest & 47 & 17.0 & 55.3 & 23.4 & 4.3 \\
8: Sustaining effort and persistence & 48 & 14.6 & 52.1 & 31.3 & 2.1 \\
9: Self-regulation & & &
\end{tabular}

Note. Guidelines 1-3 represent the principle of multiple means for representation, guidelines 4-6 represent the principle of multiple means for action and expression and guidelines 7-9 represent the principle for multiple means for engagement.

Respondents were asked about the variety of ways in which they present information (Principle 1), assess student learning (Principle 2), and engage students (Principle 3) across different units or tasks within the online course. Few online instructors offer a variety of ways simultaneously across all units or tasks for presentation of information, assessment of student learning, or student engagement. Most online instructors offer a variety of ways within most or some of the units or tasks in the course for presentation, assessment, and engagement.

Table 8

Frequency (Percent) of Overall Use of UDL Principles Within the Course

\begin{tabular}{lccc}
\hline \multicolumn{1}{c}{ Use of UDL principles } & Presentation & Assessment & Engagement \\
\hline Variety of ways simultaneously within each unit or task for & $12(14.3)$ & $14(16.7)$ & $13(15.7)$ \\
ALL units/ tasks & & & \\
Variety of ways simultaneously within each unit or task for & $30(35.7)$ & $25(29.8)$ & $31(37.4)$ \\
MOST units/ tasks (more than half) & & & \\
Variety of ways simultaneously within each unit or task for & $21(25.0)$ & $18(21.4)$ & $15(18.1)$ \\
SOME units/ tasks (less than half) & & & \\
Variety of ways ACROSS the units or tasks of the course & $16(19.1)$ & $19(22.6)$ & $19(22.9)$ \\
One way within all the units or tasks of the course & $5(6.0)$ & $8(9.5)$ & $5(6.1)$ \\
\hline
\end{tabular}




\section{Interest in Applying UDL to Online Courses}

The final section of the survey concerned faculty interest in learning about applying the guidelines to online courses. Moderate to high interest exists for learning more about each guideline (see Table 9), but concentrated interest lies with Guideline 8: Sustaining Effort and Persistence (45.5\%), Guideline 3: Comprehension (47.5\%), and Guideline 5: Expression and Communication (44.9\%).

Table 9

Faculty Interest in Learning About Applying UDL to Their Course Design

\begin{tabular}{lccccc}
\hline & & \multicolumn{4}{c}{ Interest level } \\
\cline { 5 - 6 } \multicolumn{1}{c}{ Guideline } & $\mathrm{n}$ & High & Moderate & Low & None \\
\hline 1: Perception & 97 & 33.0 & 40.2 & 17.5 & 9.3 \\
2: Language, mathematical expressions, and symbols & 98 & 31.6 & 39.8 & 18.4 & 10.2 \\
3: Comprehension & 99 & 47.5 & 35.4 & 9.1 & 8.1 \\
4: Physical action & 98 & 28.6 & 41.8 & 20.4 & 9.2 \\
5: Expression and communication & 98 & 44.9 & 33.7 & 13.3 & 8.2 \\
6: Executive function & 99 & 36.4 & 37.4 & 15.2 & 11.1 \\
7: Recruiting interest & 99 & 33.3 & 38.4 & 15.2 & 13.1 \\
8: Sustaining effort and persistence & 99 & 45.5 & 31.3 & 15.2 & 8.1 \\
9: Self-regulation & 96 & 36.5 & 39.6 & 14.6 & 9.4 \\
\hline
\end{tabular}

Note. Guidelines 1-3 represent the principle of multiple means for representation, guidelines 4-6 represent the principle of multiple means for action and expression and guidelines 7-9 represent the principle for multiple means for engagement.

Next, respondents rated the top three most valuable guidelines when designing an online course. In Table 10, the guidelines selected most often as first most valuable were Guideline 3: Comprehension (33.0\%) and Guideline 1: Perception (19.6\%). Guidelines selected most often as second most valuable were Guideline 3 (26.6\%) and Guideline 5: Expression and Communication (18.1\%). Guideline 5 (20.9\%) and Guideline 9: Self-Regulation (17.6\%) were most often selected as third most valuable. The guidelines most frequently selected among the top three were Guideline 3 (67.0\%) and Guideline 5 (51.5\%). 
Table 10

Faculty Ranking of the Top Three Most Valuable UDL Guidelines

\begin{tabular}{|c|c|c|c|c|}
\hline Guideline & $\begin{array}{c}\% \\
\text { selecting } \\
\text { first most } \\
\text { valuable } \\
(n=97)\end{array}$ & $\begin{array}{c}\% \\
\text { selecting } \\
\text { second } \\
\text { most } \\
\text { valuable } \\
(\mathrm{n}=94)\end{array}$ & $\begin{array}{c}\% \\
\text { selecting } \\
\text { third } \\
\text { most } \\
\text { valuable } \\
(\mathrm{n}=91)\end{array}$ & $\begin{array}{c}\% \\
\text { within } \\
\text { top 3 } \\
(\mathrm{n}=97)\end{array}$ \\
\hline 1: Perception & 19.6 & 11.7 & 8.8 & 39.2 \\
\hline 2: Language, mathematical expressions, and symbols & 4.1 & 3.2 & 1.1 & 8.2 \\
\hline 3: Comprehension & 33.0 & 26.6 & 8.8 & 67.0 \\
\hline 4: Physical action & 11.3 & 10.6 & 9.9 & 30.9 \\
\hline 5: Expression and communication & 15.5 & 18.1 & 19.8 & 51.5 \\
\hline 6: Executive function & 5.2 & 6.4 & 14.3 & 24.7 \\
\hline 7: Recruiting interest & 5.2 & 1.1 & 7.7 & 13.4 \\
\hline 8: Sustaining effort and persistence & 2.1 & 13.8 & 12.1 & 26.8 \\
\hline 9: Self-regulation & 4.1 & 8.5 & 17.6 & 28.9 \\
\hline
\end{tabular}

Note. Guidelines 1-3 represent the principle of multiple means for representation, guidelines 4-6 represent the principle of multiple means for action and expression and guidelines 7-9 represent the principle for multiple means for engagement.

\section{Discussion}

The purpose of this study was to identify and prioritize instructors' needs for successful application of UDL principles in online course design. The first research question guiding this study pertained to instructor familiarity regarding UDL principles and guidelines. Sixty-two percent of the respondents reported that they were familiar with at least one UDL guideline. This provides evidence that there are opportunities for faculty professional development to increase familiarity and raise awareness of UDL guidelines for online course development. The UDL framework provides principles and guidelines to assist faculty in creating an inclusive culture which supports the mission of the university to promote equity and accessibility to a highquality education. Capp (2018) suggests that professional development in UDL should not be a general workshop examining the broader underlying principles, but instead aim to target on-demand resources addressing specific UDL principles and guidelines to increase confidence in implementing the UDL framework.

Importantly, respondents were most familiar with guidelines aligned with perception, expression, and communication. These guidelines are similar to quality rubric design standards such as QM's standards for assessments that "are sequenced, varied, and suited to the level of the course" (Quality Matters, 2018, p. 1). Participants often indicated they learned about UDL through professional development, which suggests prior coursework of potential new faculty should be considered as an important resource for advancing 
UDL adherence. Additionally, existing QM workshops given on campus may be serving to propagate certain UDL concepts, particularly related to raising awareness. Given the emphasis of QM on applying standards to instructional materials, future professional development should encourage additional technical steps toward the creation of accessible electronic materials.

The second research question examined the current status of UDL practice. The guidelines used most frequently in course design were Guideline 3 (69.8\%) which suggests that options be provided for comprehension and Guideline 5 (64.9\%), which suggests that options should be provided for expression and communication. Interestingly, the existing research seems to prioritize Guideline 1, providing options for perception, as a necessary introductory step to implement UDL online (Dell et al., 2015; Robinson \& Wizer, 2016; Tobin, 2014). While Guideline 1 was still mentioned by about half of the respondents, opportunities to support faculty in generating multiple content alternatives exist.

The level of practice for Guideline 3 is also worth noting. In addition to being the most frequently used, Guidelines 3 and 5 were rated at the highest levels of implementation with the ability to use them without assistance. This suggests a field-initiated strategy for adoption aligned with Guideline 3 that many instructors find practical and feasible. Still, relatively few reported they allowed students options on how to represent their mastery of the content. This is consistent with Capp's (2018) findings indicating that faculty were more confident in providing various instructional materials than they were letting students create different products to show mastery. Student choices should provide multiple options for how students engage with the material and how they participate in assessments. An example would be to provide options for how to produce a product that shows students have mastered an objective such as writing a paper, producing a video, or creating a presentation. Detailed examples of how to apply UDL principles with student choices centered on student interests, motivations, and needs were provided by Morra and Reynolds (2010).

Tobin (2014) suggested starting with text by writing out content, then creating audio and video alternatives, and finally allowing students to "let 'em do it their way" (p. 16). Of course, it is important to recognize that providing options may create additional work for faculty. This may explain why faculty are in favor of providing some options-when it is convenient-but hesitate to do so in all circumstances. However, as Tobin has noted, expressive options can also create more engaging grading sessions for faculty. Since only about one-third of the respondents indicate that they need assistance to apply most of the guidelines, further support is still needed. Additionally, more research is needed to elucidate the types of courses and skills being taught for which faculty need assistance providing various types of presentation, assessment, and engagement options.

The least used guidelines were Guideline 2 (38.8\%) suggesting that options be provided for language and support, and Guideline 4 (42.1\%) suggesting options be varied for physical action. These guidelines were also two of the lowest rated in terms of faculty comfort with implementation. While these may in fact be more difficult to implement, one reason could be a lack of clarity as to what each guideline really means in practice. Since UDL guidelines were established before the mainstreaming of online courses, the ideas of physical action and language support are not immediately apparent. Online courses may seem like unlikely venues to promote physical action, but the lack of application is evidence of unfamiliarity of this specific guideline in online learning contexts. Physical action may mean how the student is physically interacting 
with the technology in the online learning environment such as a touch screen or an image scavenger hunt. Only $2.7 \%$ of faculty rated their comfort in applying Guideline 4: Physical Action at the highest level, that of mentoring others. As UDL migrates to the online context, it is important to clearly translate the meaning of each guideline, and provide faculty with good, operationalized examples of their application (Rao, et al., 2014).

The third research question examined interest in learning more about UDL for online courses. While there was moderate to high interest in learning more about all of the guidelines, the highest interest lies with Guideline 3: Comprehension (47.5\%), Guideline 8: Sustaining Effort and Persistence (45.5\%), and Guideline 5: Expression and Communication (44.9\%). Guidelines 3 and 5 were also ranked highly by faculty in terms of importance. On the contrary, Guideline 8 was rated as one of the lowest in terms of importance, but one of the highest in terms of interest. Further research is needed to understand the dichotomy in this case, as well as to clarify the reasons why certain guidelines were not viewed as important, including the three guidelines that comprise the engagement principle. Recent research has highlighted the importance of engagement in the online context. For example, Cho and Shen's (2013) recent study of self-regulation (see Guideline 9) in online learning showed students' intrinsic goal orientation and self-efficacy were important for academic achievement.

Finally, we showed that similarities exist between familiarity and interest in the guidelines, pointing to the importance of future professional development on UDL. If faculty learn to apply the options that UDL prescribes, we would expect to see interest in UDL grow as well. An important consideration for professional development may be digital tools. Although not explicitly detailed in the Results section due to the lack of an explicit connection of digital tools with UDL, our study found a lack of training to use digital tools. Instructors' awareness of digital tools and their abilities to support UDL guideline implementation could have a significant impact on the success of online course design. The UDL guidelines offer many instructional best practices to differentiate for diverse learners; therefore, the research team suggests promoting professional development on UDL guidelines in conjunction with digital tools for online instructors.

\section{Conclusion}

The results from this survey point to a need for higher education practitioners, researchers, and administrators to further allocate resources for effective training on the application of UDL guidelines in online course design. Many online instructors who took this survey admitted a lack of knowledge about UDL. However, there are also many online instructors who have been trained or have extensive practice implementing UDL guidelines in their online teaching, and may be consulted to offer training for their colleagues or identify the best practices for online course design. Yet, even those with familiarity and high implementation of some UDL guidelines express a need for and interest in learning about other UDL guidelines. For the adoption of the guidelines to be widespread in the online learning context, investigating the faculty decision-making and adoption process is warranted. Exploratory research that identifies concrete examples of best practices in all disciplines would be beneficial. This would help designers and faculty connect the guidelines to current online course design practices. 
Familiarity, Current Use, and Interest in Universal Design for Learning Among Online University Instructors Westine, Oyarzun, Ahlgrim-Delzell, Casto, Okraski, Park, Person, and Steele

\section{Acknowledgements}

This research was funded by The University of North Carolina at Charlotte Scholarship of Teaching and Learning Program. 


\section{References}

Al-Azawei, A., Serenelli, F., \& Lundqvist, K. (2016). Universal design for learning (UDL): A content analysis of peer-reviewed journal papers from 2012 to 2015. J ournal of the Scholarship of Teaching and Learning, 16(3), 39-56. doi:10.14434/josotl.v16i3.19295

Allen, I. E. \& Seaman. J . (2016). Online report card: Tracking online education in the United States. Babson Survey Research Group and Quahog Research Group, LLC. Retrieved from http:// onlinelearningsurvey.com/reports/onlinereportcard.pdf

Americans With Disabilities Act of 1990, Pub. L. No. 101-336, § 2, 104 Stat 328 (1991).

Barnard-Brak, L., \& Sulak, T. (2010). Online versus face-to-face accommodations among college students with disabilities. American J ournal of Distance Education, 24, 81-91. doi:10.1080/08923641003604251

Bauder, D., \& Simmons, T. (2017). Digital pedagogy: Embedding universal design for learning (UDL) strategies in online courses. In P. Resta \& S. Smith (Eds.), Proceedings of Society for Information Technology \& Teacher Education International Conference (pp. 127- 132). Austin, TX: Association for the Advancement of Computing in Education.

Capp, M.J . (2017). The effectiveness of universal design for learning: A meta-analysis of literature between 2013 and 2016, International J ournal of Inclusive Education, 21, 791- 807. doi:10.1080/ 13603116.2017.1325074

Capp, M. J . (2018). Teacher confidence to implement the principles, guidelines, and checkpoints of universal design for learning. International J ournal of Inclusive Education. Advanced online publication. doi:10.1080/13603116.2018.1482014

Casper, B., \& Leuichovious, D. (2005). Universal design for learning and the transition to a more challenging academic curriculum: Making it in middle school and beyond. Teacher Education and Special Education. 36, 7-27. doi:10.1177/ 0888406412446178

CAST. (2018). Universal design for learning guidelines version 2.2. Retrieved from http://udlguidelines.cast.org

Cho, M. H., \& Shen, D. (2013). Self-regulation in online learning. Distance Education, 34, 290- 301. doi:10.1080/01587919.2013.835770

Dell, C. A., Dell, T. F., \& Blackwell, T. L. (2015). Applying universal design for learning in online courses: Pedagogical and practical considerations, J ournal of Educators Online, 12, 166-192. Retrieved from https:// www.thejeo.com/archive/archive/2015_122/dell_articlepdf 
Dillman, D. A., Smyth, J . D., \&Christian, L. M. (2014). Internet, phone, mail, and mixed-mode surveys: The tailored design method (4th ed.). Hoboken, NJ : J ohn Wiley \& Sons, Inc.

Eberle, J ., \& Childress, M. (2006). Universal design for culturally diverse online learning. In A. Edmundson (Ed.), Globalized e-learning cultural challenges (pp. 239-254). Hershey, PA: Idea Group, Inc.

Hall, T. E., Cohen, N., Vue, G., \& Ganley, P. (2015). Addressing learning disabilities with UDL and technology: Strategic reader. Learning Disability Quarterly, 38, 72- 83. doi: $10.1177 / 0731948714544375$

He, Y. (2014). Universal design for learning in an online teacher education course: Enhancing learners' confidence to teach online. MERLOT J ournal of Online Learning and Teaching, 10, 283- 297. Retrieved from http://jolt.merlot.org/vol10no2/he_0614.pdf

Katz, J . (2012). Teaching to diversity: The three-block model of universal design for learning. Winnipeg, MB: Portage and Main Press.

Keeler, C. G. \& Horney, M. (2007). Online course designs: Are special needs being met?, The American J ournal of Distance Education, 21, 61- 75. doi:10.1080/08923640701298985

Krejcie, R. V., \&Morgan, D. W. (1970). Determining sample size for research activities. Educational and Psychological Measurement, 30, 607-610. doi:10.1177/ 001316447003000308

Kumar, K. L., \&Wideman, M. (2014). Accessible by design: Applying UDL principles in a first year undergraduate course. Canadian J ournal of Higher Education, 44(1), 125- 147. Retrieved from http://journals.sfu.ca/cjhe/ index.php/ cjhe/ article/ view/ 183704/ 184422

Morra, T., \& Reynolds, J . (2010). Universal design for learning: Application for technology-enhanced learning. Inquiry: The J ournal of the Virginia Community Colleges, 15(1), 43- 51. Retrieved from https:// commons.vccs.edu/inquiry/vol15/iss1/ 5

Quality Matters. (2018). Specific review standards from the quality matters higher education rubric (6th ed.). Retrieved from https:// www.qualitymatters.org/ sites/ default/ files/PDFs/ StandardsfromtheQMHigherEducation Rubric.pdf

Rao, K., Ok, M. W., \& Bryant, B. R. (2014). A review of research on universal design educational models. Remedial and Special Education, 35, 153- 166. doi:10.1177/ 0741932513518980

Rao, K., \& Tanners, A. (2011). Curb cuts in cyberspace: Universal instructional design for online courses. J ournal of Postsecondary Education and Disability, 24, 211- 229. Retrieved from http:// www.aheadarchive.org/uploads/publications/JPED/jped_24_3/JPED\%2024_3_FULL\%20DOCUMENT.pd f 
Robinson, D. E., \&Wizer, D. R. (2016). Universal design for learning and the quality matters guidelines for the design and implementation of online learning events. International J ournal of Technology in Teaching \& Learning, 12(1), 17- 32.

Ryan, J . (2007). Learning disabilities in Australian universities: Hidden, ignored, and unwelcomed. J ournal of Learning Disabilities, 40, 436- 442.

doi:10.1177/00222194070400050701

The University of North Carolina at Charlotte. (2014). Mission statement. Retrieved from https:// chancellor.uncc.edu/institutional-planning/mission-statement

Tobin, T.J . (2014). Increase online student retention with universal design for learning. The Quarterly Review of Distance Education, 15, 13- 48.

Wiggins, G. \& McTighe, J . (2005). Understanding by design. Alexandria, VA: Association for Supervision and Curriculum Development. doi:10.14483/ calj.v19n1.11490

\section{Athabasca} University

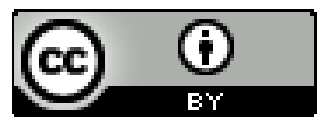

